\title{
Experimentação real versus experimentação ideal no ensino de ciências e a prática do pensamento crítico
}

\begin{abstract}
Experimentation real versus ideal experimentation in science teaching and practice of critical
\end{abstract} thinking

\author{
G. G. Santos*; D. N. Souza \\ ${ }^{1}$ Programa de Pós-Graduação em Ensino de Ciências e Matemática, Universidade Federal de Sergipe, 49100-000, São \\ Cristovão-Sergipe,Brasil
}

(*grazianequimica@gmail.com)

(Recebido em 02 de fevereiro de 2016; aceito em 29 de outubro de 2016)

\begin{abstract}
Este artigo tem por finalidade investigar sobre o entendimento dos mestrandos do Programa de Pós-graduação em Ensino de Ciências e Matemática a respeito do uso de atividades práticas no Ensino de Ciências. A abordagem envolveu os entrevistados na tentativa de identificar e refletir quanto as potencialidades da experimentação na formação do pensamento crítico, e quando é necessário utilizar um experimento real ou ideal. A metodologia empregada permitiu perceber a interferência do ensino indutivista porque alguns dos entrevistados ainda utiliza a experimentação como comprovação de teoria.

Palavras- chave: Experimentação; Ensino de Ciências; Professores

This article aims to investigate the understanding of the masters of the Graduate Program in Science and Mathematics Teaching about the use of practical activities in science education. The approach involved respondents to identify and reflect as the trial potential in the formation of critical thinking, and when it is necessary to use a real or ideal experiment. The methodology allowed us to perceive the interference of inductive teaching because some of the respondents still use the trial as a theory of evidence. Keywords: Experimentation; Science education; Teachers.
\end{abstract}

\section{INTRODUÇÃO}

Como entender a experimentação no ensino de química sob uma perspectiva didática? Como a escola pode contribuir para a realização da atividade experimental no ensino de ciências? Qual a contribuição da atividade prática para um aprendizado significativo? Essas são algumas indagações que muitos professores podem ter ao pensar em levar para sala de aula uma atividade que envolva experimentos, no qual faça com que o aluno tenha uma visão mais crítica sobre o meio em que vive.

As atividades experimentais são instrumentos que proporcionam o desenvolvimento científico sobre determinados fenômenos abordados em sala de aula, além de explorar a capacidade intelectual e a construção da visão crítica de determinados fatos, possibilitando a formação do caráter e da personalidade, incluindo no meio científico e social. Nessa perspectiva, a interação do cotidiano escolar com a aplicação de conceitos elaborados cientificamente e as atividades experimentais levam os alunos a fazerem questionamentos que são importantes para a promoção da aprendizagem. Segundo Silva e Zanon:

As atividades práticas assumem uma importância fundamental na promoção de aprendizagens em ciências e, por isso, consideramos importante valorizar propostas alternativas de ensino que demonstrem essa potencialidade da experimentação: a de ajudar os alunos a aprender através do estabelecimento de inter-relações entre os saberes teóricos e práticos [1]. 
Mas isso não é simples, pois relacionar os conteúdos com os conhecimentos prévios dos alunos é algo difícil, porém é um desafio que deve ser compreendido como forma de relacionar a experimentação com as situações do cotidiano. Muitos os professores podem se utilizar de metodologias que se alicerçam nas atividades experimentais, e que facilitam a compreensão de conceitos além de, proporcionar o ensino e a aprendizagem naquilo em que os indivíduos têm de melhor, a curiosidade. Pois, ter o aluno como um ser passivo é menos gratificante do que motiválo a fazer questionamentos, a serem curiosos, porque a arte de questionar é uma ferramenta importante e também um indicativo para nós professores de que está havendo uma mudança na forma como os alunos estão assimilando os conteúdos. Assim, nós, professores, precisamos fazer do Ensino de Ciências um caminho para desenvolver atividades que amplie a criatividade dos alunos, pois isso contribui para eles conhecerem a ciência como um ponto de partida para que se tornem cidadãos críticos e a desenvolverem um pensamento crítico e reflexivo sobre o conhecimento científico adquirido.

Neste artigo apresentamos o resultado de uma pesquisa cujo objetivo foi conhecer a visão dos alunos de mestrado em Ensino de Ciências e Matemática da Universidade Federal de Sergipe sob a importância de desenvolver a experimentação como ferramenta didática.

\section{Experimentação real versus experimentação ideal}

Como se adequar à realidade do aluno e promover a de um ensino com significado ao mesmo tempo? Parece ser um tanto complexo, mas, a experimentação está inserida no processo de ensino e aprendizagem onde muitos docentes não sabem diferenciar e muito menos relacionar o que é necessário para tornar a atividade prática ideal em real. Assim, alguns autores trazem a atividade experimental como um objeto didático de característica versátil, colocando o professor como mediador sob um olhar construtivista do ensino. Como afirma Filho (2000) [2]:

A atividade experimental deve ser entendida como um objeto didático, [...]. Como objeto didático sua estrutura deve agregar características de versatilidade, de modo a permitir que seu papel mediador se apresente em qualquer tempo e nos mais diferentes momentos do diálogo sobre o saber no processo ensino-aprendizagem. E, principalmente, é um objeto de ação que, manipulado didaticamente pelo professor, irá se inserir no discurso construtivista facilitando a indução do fenômeno didático que objetiva o ensino de saberes.

Essa versatilidade das atividades experimentais implica em três maneiras distintas de desenvolvê-las como um objeto de ação diferente, ou relacioná-la para aproximar à realidade do aluno, são elas: Atividades Experimentais Ilustrativas, Investigativas e Problematizadoras.

As ilustrativas ou demonstrativas servem como meio de comprovação de teorias, são as famosas práticas tipo "receita de bolo", onde o aluno recebe um roteiro por meio do qual deverá realizar o experimento e fazer um relatório, que poderá não contribuir para a sua aprendizagem, mas irá comprovar que a teoria está correta. Esse é o tipo que os livros didáticos trazem, sem muitos questionamentos e problematizações, apenas comprovações, onde o aluno utiliza seu tempo apenas buscando resultados e verificando se está correto e promovendo uma aprendizagem mecanizada. Segundo Hartwig (2008), "a experimentação ilustrativa geralmente é mais fácil de ser conduzida. Ela é empregada para demonstrar conceitos discutidos anteriormente, sem muita problematização e discussão dos resultados experimentais [3].”.

Porém, como professores podemos nos utilizar desse passo a passo para recontextualizar e propor diálogos que levem a ações construtivistas na sala de aula e a novos cenários de descoberta, nas atividades em sala de aula. Ou seja, podemos fazer desse passo a passo um bom instrumento de avaliação. Para isso, algumas estratégias são sugeridas, como as apresentadas pela autora Oliveira (2010) [4]:

- Antes da realização da demonstração, explicar o que se pretende fazer na aula e perguntar aos alunos o que eles esperam que aconteça, solicitar suas explicações 
prévias para os possíveis eventos. Essa estratégia possibilita a verificação das concepções alternativas dos alunos.

- Durante a realização do experimento, solicitar que os alunos observem cuidadosamente todas as etapas e destaquem o que lhes chamou atenção. Solicitar que os alunos façam registros escritos do que foi observado.

- Ao final da demonstração, questionar novamente os alunos sobre as explicações para o experimento apresentado. Em seguida, apresentar (ou revisar) o modelo científico que explica os fenômenos observados e comparar tais explicações com as ideias prévias dos alunos.

- Utilizar questionários para serem respondidos em grupos sobre a atividade realizada (como tarefa de casa, por exemplo), de modo que os alunos possam novamente discutir sobre os fenômenos observados e os conteúdos científicos abordados na aula.

Nas atividades investigativas, o professor propõe uma atividade e o estudante pesquisa, planeja, executa e discute os resultados. Porém, esse tipo de ação exige um tempo maior para a sua realização e esse é o grande problema encontrado.

"As atividades experimentais investigativas podem ser feitas por demonstrações pelo professor ou então realizadas pelos alunos. Quando aquele realiza demonstrações, não necessariamente significa que estes não poderão participar da construção de um conceito, pelo contrário,[...] ao conduzir o experimento de forma demonstrativa, questionar os estudantes e propuser desafios, essa atividade possivelmente terá as características de uma atividade de investigação, na qual estes argumentam e expõem seus raciocínios. Entretanto, se o professor apenas demonstrar um experimento para comprovar uma teoria e não o problematizar, essa atividade perderá grande parte das potencialidades que a experimentação investigativa pode desenvolver [5]."

De acordo com Suart (2010), é evidente que a relação professor - aluno e o papel representado por cada um na realização da atividade para juntos alcançarem os objetivos da aprendizagem. Essa parceria faz com que o aluno saia da passividade durante a aula e comece a agir sobre o próprio processo de pensamento, e participando da construção do conhecimento crítico e reflexivo.

E por último, temos as atividades experimentais baseadas na problematização, pois é tratada como uma alternativa de resolver problemas a partir de um contexto, que segundo Gonçalves e Marques (2006), "problematizar as atividades experimentais com o objetivo de motivar não significa negar tal possibilidade [6]". Essa possibilidade a qual os autores se referem é aquela que faz do aluno um ser motivador da realização dessas atividades práticas, realçando que elas não precisam ter caráter facilitador da aprendizagem, mas como um dos elementos que fazem parte do processo. Logo, podemos entender a experimentação problematizadora sobre a perspectiva dos três momentos pedagógicos proposto por Delizoicov (2014) [7]: Problematização Inicial (PI), Organização do conhecimento (OC) e Aplicação do conhecimento (AC).

Na problematização inicial, o experimento deve ser mostrado antes da explanação da teoria com o intuito de instigar os alunos para os questionamentos futuros que iram servir de alicerce para as explicações do assunto abordado. Os estudantes fazem suas anotações, constatando as informações fornecidas pela atividade e, também, suas indagações e reflexões sobre os resultados da atividade, a fim de elaborar possíveis explicações para seus resultados. Quanto tal problematização, Delizoicov define:

"Problematização Inicial: apresentam-se questões ou situações reais que os alunos conhecem e presenciam e que estão envolvidas nos temas. Nesse momento pedagógico, os alunos são desafiados a expor o que pensam sobre as situações, a fim de que o professor possa ir conhecendo o que eles pensam. Para os autores, a finalidade desse momento é propiciar um distanciamento crítico do aluno ao se defrontar com as interpretações das situações propostas para discussão, e fazer com 
que ele sinta a necessidade da aquisição de outros conhecimentos que ainda não detém [7]."

Assim, é possível perceber que o papel do professor não é fornecer explicações prontas, mas problematizar com os alunos suas observações, a leitura do experimento, fazendo-os reconhecer a necessidade de outros conhecimentos para interpretar os resultados experimentais [3].

$\mathrm{Na}$ organização do conhecimento, a problematização feita com os alunos é realizada a partir das anotações. Com o auxílio do professor, as informações são organizadas, discutidas e relacionada com os conceitos elaborando possíveis hipóteses para os resultados obtidos.

"Organização do Conhecimento: momento em que, sob a orientação do professor, os conhecimentos de física necessários para a compreensão dos temas e da problematização inicial são estudados [7]."

Nesse segundo momento, os alunos têm a possibilidade de formular ou reformular as suas ideias, abordando os conceitos científicos, com a finalidade se tornar cada vez mais críticos. Na aplicação do conhecimento, o professor aborda tudo o que foi anotado pelos alunos, auxiliando-o na análise e interpretação da situação que determina a explanação do conteúdo e que venham a ser compreendidas com auxílio dos conhecimentos já adquiridos.

Aplicação do Conhecimento: momento que se destina a abordar sistematicamente o conhecimento incorporado pelo aluno, para analisar e interpretar tanto as situações iniciais que determinaram seu estudo quanto outras que, embora não estejam diretamente ligadas ao momento inicial, possam ser compreendidas pelo mesmo conhecimento [7].

Nesse terceiro momento é onde a atividade experimental efetivamente entra em cena. O professor pode se utilizar do experimento para explanar conceitos, fazendo com que os alunos os interpretem e saibam aplicá-lo em contextos diferenciados. Outra forma de utilizar a experimentação nesse terceiro momento é quando o professor descreve todo o procedimento experimental, apresenta os resultados obtidos e solicita que seus alunos expliquem, de forma que expressem seu conhecimento. Logo, segundo Guimarães et al (2013) [8], podemos definir atividades experimentais problematizadoras como aquelas em que os estudantes não recebem apenas um roteiro para seguir e ideias prontas: ele observa, reflete e tem os seus conhecimentos prévios levados em consideração pelo professor.

Diante de toda essa discutição, podemos mostrar que, entre outras, a atividade experimental problematizadora é uma das aque mais desperta questionamentos. E o ato de questionar uma forma de instigar o pensamento crítico. Assim, a base do pensamento crítico, segundo Tenreiro - Vieira [9], são: "observar, procurar semelhanças e diferenças, formular questões e problemas, planificar e levar a cabo investigações apropriadas e fazer inferências e comunicá-las com base nos dados obtidos [9]". Essas etapas resumem o processo experimental, no qual nos possibilita conceituar o que venha a ser a experimentação real e ideal.

A experimentação ideal é aquela em que o professor faz usos dos conhecimentos prévios dos seus alunos, relacionando com o conteúdo abordado em sala de aula e a realização da atividade prática como mecanismo de complementação, interligando todos os tipos de atividade (ilustrativa, investigativa e problematizadora), com o intuito de ensinar e também de aprender, realizando uma troca de saberes e promovendo uma aprendizagem diferenciada e significativa, seja para o docente quanto para o discente. Já a experimentação real é aquela que nos deparamos diariamente, não possui nenhum tipo de diálogo e nem é utilizada como ferramenta de promoção de saberes, mas, sim utilizada como demonstração, como atividade extra que exige relatório para definição de uma nota, e que não irá contribuir significativamente para o desenvolvimento científico do aluno.

Para que as atividades experimentais produzam e forneçam os elementos desejáveis à configuração teórica preestabelecida, se faz necessária a utilização de práticas 
coletivas compartilhadas como meio de construção e validação do conhecimento em questão [2].

O processo de validação do conhecimento citado pelo autor é uma técnica na qual o professor trará resultados, sendo estes positivos ou negativos. Uma das formas de validar um conhecimento é aplicando um questionário, pois, por meio deles será mais fácil demonstrar habilidades.

\section{MATERIAL E MÉTODOS}

Segundo Silva et al. (2015) [10], as atividades experimentais são utilizadas na maioria das vezes, apenas com o objetivo de demonstração ou reafirmação de teorias, provocando nos alunos uma falsa construção do conhecimento.

Em vista disso, a pesquisa possui caráter exploratório, de cunho qualitativo e foi proposto um questionário individual para quarenta e cinco professores, que foi enviado por e-mail. A análise das propostas dadas por esses profissionais serviu para conhecer a visão deles sobre o papel da experimentação no Ensino de Ciências, o que possibilitou conhecer as formas diferenciadas de pensamento sobre o tema fornecido e a proposição de soluções e visões que possam trazer novas propostas de utilização da ferramenta didática. $\mathrm{O}$ público alvo da pesquisa foram professores formados em Licenciatura em Química, Biologia, Física e Pedagogia, que atualmente estão cursando mestrado em Ensino de Ciência e Matemática da Universidade Federal de Sergipe.

Ainda conforme Santos et al. (2015) [11], a escolha por um estudo qualitativo nos fornece uma compreensão maior da atividade investigativa, onde podemos identificar traços da realidade atingindo o nosso objetivo que é entender através das respostas o que está ocorrendo no mundo da educação.

O questionário foi constituído de sete questões abertas, e este método foi escolhido porque consiste numa forma de alcançar os objetivos da pesquisa, além de possuir vantagens, conforme Marconi e Lakatos (2003) [12], como uma maior economia de recursos materiais, liberdade de respostas, mais segurança do respondente, menor risco de distorção, possibilitando atingir um maior número de pessoas, dentre outras vantagens.

Além de se ter o intuito de conhecer e verificar a opinião dos entrevistados sobre a importância de desenvolver atividades experimentais, buscou-se conhecer também os tipos e quanto à classificação da experimentação, se real ou ideal.

\section{RESULTADOS E DISCUSSÃO}

Inicialmente, deixamos claro que os resultados aqui descritos foram baseados nas respostas de apenas cinco (12\%) dos entrevistados, sendo desses três licenciados em química, um licenciado em biologia e um licenciado em matemática, porque apenas esses tiveram disponibilidade de responder o questionário e devolvê-lo.

A questão inicial refere-se à opinião do professor quanto à função da atividade experimental quando aplicada na forma passo a passo. "Em sala de aula, que tipo de atividade pode ser promovida com um experimento tipo "receita de bolo?" Os professores apresentaram três linhas de justificativas: em relação ao aluno, às aulas e ao livro didático, como tabela abaixo: 
Tabela 1: A experimentação sobre uma perspectiva tipo receita de bolo

\begin{tabular}{|c|c|c|}
\hline Quanto ao aluno & Quanto à aula & Quanto ao livro didático \\
\hline $\begin{array}{l}\text { "Uma atividade } \\
\text { representada apenas por } \\
\text { aquilo que o aluno } \\
\text { reproduz somente o que } \\
\text { pede o roteiro do } \\
\text { experimento, sem } \\
\text { discussões e indagações } \\
\text { no decorrer da prática." }\end{array}$ & $\begin{array}{c}\text { "Aulas que envolva coleta } \\
\text { de dados para fins } \\
\text { específicos." }\end{array}$ & $\begin{array}{l}\text { "As que são propostas nos } \\
\text { livros didáticos, no início } \\
\text { ou no fim dos capítulos, } \\
\text { como tentativas de fixar } \\
\text { ou introduzir um } \\
\text { conteúdo." }\end{array}$ \\
\hline $\begin{array}{l}\text { "Uma atividade em que o } \\
\text { aluno é um mero executor } \\
\text { do experimento, não } \\
\text { questiona, não discute, } \\
\text { pois seu objetivo é } \\
\text { executar o experimento de } \\
\text { acordo com um roteiro } \\
\text { prévio que contém todas } \\
\text { as etapas a serem seguidas } \\
\text { e coletar os dados." }\end{array}$ & $\begin{array}{c}\text { "Seria aquele em que o } \\
\text { professor entrega aos } \\
\text { alunos um "passo a passo" } \\
\text { a ser seguido, isto é, uma } \\
\text { sequência metodológica } \\
\text { para atingir um } \\
\text { determinado resultado, } \\
\text { sendo feita apenas uma } \\
\text { verificação desse } \\
\text { fenômeno, sem estimular a } \\
\text { capacidade de percepção e } \\
\text { de investigação dos/as } \\
\text { alunos/as." }\end{array}$ & Não opinou. \\
\hline
\end{tabular}

Com base nas respostas obtidas, é notório que os professores sabem que a atividade não produz uma aprendizagem significativa, mas aplicam porque veem nos livros didáticos, servindo para comprovar a teoria e determinar resultados. Como afirma Galiazzi (2014) [13], ainda se trabalha com empirismo para comprovar teoria, utilizando aspectos tradicionais do ensino.

A segunda questão refere-se ao uso das atividades experimentais e a maneira pela qual o professor faz uso das mesmas para reforçar, problematizar, comprovar os conteúdos dados anteriormente ou para introduzir novos conteúdos. "Você acha que atividades que envolvam experimentos são, extremamente, necessárias para que o aluno compreenda determinado conteúdo?"

Os resultados apontam que três dentre os cinco professores entrevistados acreditam que existe a necessidade de realizar atividades experimentais para contribuir para a compreensão do assunto:

Considero que sejam importantes as atividades experimentais, para compreender determinados importantes, pois é fundamental partir de um fenômeno do ponto de vista macroscópico, seguido de uma explicação submicroscópica.

Sim, porém, a depender do modo como ela seja conduzida, possa ser que não tenha efeitos positivos, podendo até prejudicar o processo de ensino-aprendizagem.

Sim, para algumas áreas do conhecimento.

Sendo assim, é evidente que o docente entenda que essa ferramenta serve de estímulo para, além dos motivos aqui já citados anteriormente, para o convívio em grupo, por meio de um planejamento, evitando contratempos, como quando o experimento não dá certo ou quando ocorrem imprevistos que levam a resultados não planejados.

[...]é essencial que o professor de ciências entenda que a aula experimental pode $e$ deve ser usada como uma ferramenta importante, para estimular não só o aprendizado, como também o raciocínio e a convivência em grupo, desenvolvendo 
habilidades que normalmente numa aula teórica expositiva não é possível fazer. Porém,mais prejudicial que a ausência dessas aulas talvez seja a prática desorganizada das mesmas, não permitindo ao aluno a compreensão dos fatos ou o desenvolvimento de raciocínio lógico [14].

Um dos entrevistados informou que não é necessária a utilização de experimentos para o aluno compreender um assunto, embora ele entendia que pudessem ser úteis, dependendo de que forma são colocados no planejamento das atividades.

Não, mas podem contribuir dependendo de como seja conduzido em sala de aula. Nem sempre, o professor-orientador acrescenta de forma correta o experimento no planejamento.

Outro ainda se mostra em dúvida em relação da postura do professor frente à atividade experimental e a sua finalidade, pois a sua aplicação é o que norteará a formação do conhecimento científico.

Depende de como o professor aborda o experimento em sala de aula. Se o professor utiliza o experimento apenas como demonstração de modo que comprove o conteúdo ou se o professor usufrui do experimento para contextualizar, problematizar de modo que o aluno pense, questione e construa seu conhecimento científico com base na experimentação.

O terceiro questionamento busca compreender a opinião dos entrevistados com relação ao emprego de materiais alternativos na realização de atividades experimentais, como uma metodologia de aprimoramento a maneira como os assuntos são explicados: "Alguns autores defendem a ideia de que muitos experimentos podem ser feitos com materiais alternativos. Você, professor, acredita que a utilização desses métodos facilita a preparação e realização de atividades experimentais em sala de aula?". Todos os entrevistados afirmaram que a utilização de material alternativo facilita a realização da prática, seja para alunos conhecerem o material, seja pela falta de recursos oferecidos pelas instituições públicas, seja pelo baixo custo ou até mesmo a questão da motivação. Eis, algumas das respostas:

Sim. Mas, depende dos sujeitos envolvidos e da unidade escolar. O uso dos materiais alternativos pode contribuir como ferramenta para auxiliar o aprendizado. No entanto, tem-se que ter cuidado para não parecer que a ciência é lúdica e simples. Sempre é preciso demonstrar o aspecto científico, com destaque para técnicas e procedimentos, para que a ciência não pareça algo utópico e longe da realidade do aprendiz.

Digamos que sim. Primeiro, os materiais são na maioria das vezes de conhecimento dos alunos; segundo, o valor é de baixo custo e terceiro, até os próprios alunos podem usar da criatividade para preparar o material instigando a motivação dos alunos, pois os mesmos estarão envolvidos na preparação e realização de tal experimento.

Sim. Sabemos que principalmente no ensino público há uma carência de materiais laboratoriais, como, por exemplo, vidrarias, que podem ser substituídas por outros materiais, até mesmo recicláveis, supriindo essa falta, sem prejudicar o andamento de atividades experimentais que ola professor/a deseja trabalhar em sala de aula.

Diante dos relatos, é notória que ainda existe por parte dos professores a necessidade de se ter um laboratório dentro da escola, porém, é preciso abrir horizontes e criar novas possibilidades de realizar experimentos com materiais diferentes, que levem a entender que a ciência além do seu caráter científico pode ter um aspecto lúdico, o que contribui para levá-los a construção do conhecimento científico. 
A avaliação do conhecimento feita através de questionários é uma das técnicas que os professores se utilizam, principalmente quando envolve a investigação, para verificar a fixação do conteúdo ou para ver se a atividade surtiu algum tipo de aprendizado. Essa técnica é composta de questões que podem ser de cunho empírico ou socioeconômico, de baixo custo e fácil manuseio. Logo, utilizá-la como complementação da experimentação é uma das alternativas mais utilizadas pelos docentes. Para entender a visão dos entrevistados a respeito dessa metodologia, foi perguntado. "Quando um professor realiza um experimento muita das vezes a sua finalização é com um questionário. Você acredita que este tipo de questionário contribui para a aprendizagem do aluno?" Eis algumas respostas:

Sim, não tem sentido realizar uma experimentação se não fizer o aluno pensar, do contrário recai no problema da experimentação com um único fim, a experimentação pela experimentação, somente.

Talvez, depende do objetivo do/a professor/a para aquela atividade.

Não. Penso que se deve dar sugestões de pesquisa e de reflexão sobre os assuntos trabalhados no experimento, mas que eles tenham uma relação com o cotidiano do aluno contextualizando os termos, experimentos e conceitos com algo que tenha importância na vida do aluno.

Se o professor trabalhar esse questionário de modo que as respostas dos alunos sejam discutidas em sala de aula juntamente com eles de tal modo que haja a construção do conhecimento é possível que se obtenha uma aprendizagem contínua. Nesse sentido, é importante destacar que os alunos precisam acompanhar, entender e compreender se as suas respostas estarão coerentes ou não com a determinada atividade, pois muitas vezes o conhecimento do senso comum não condiz com o científico.

Portanto, atividades experimentais são importantes, se vinculadas a uma metodologia adequada de discussão e análise do que está sendo estudado. [15]

A quinta questão traz o seguinte enunciado: Justifique a afirmação: "A experimentação é importante para facilitar a aprendizagem dos conceitos de ciências [16]." Com a análise das respostas sobre essa afirmação buscou-se compreender a concepção dos entrevistados quanto à natureza pedagógica da atividade prática e sua influência na aprendizagem, que segundo Piletti e Rossato (2011) [16], "ensinar é provocar o desequilíbrio da mente do estudante para que ela busque o reequilíbrio, numa reconstrução de novos esquemas, ou seja, que ele aprenda [17]." Logo, as respostas obtidas, demonstram a experimentação como uma ferramenta, que se planejada de acordo com a realidade do meio, pode contribuir significativamente para o aprendizado.

Tudo que o aluno possa manipular contribui para reforço positivo de aprendizagem, modificando internamente seu conhecimento.

É preciso que a experimentação não seja vista e realizada como receita de bolo, mas que esta seja planejada de modo que o aluno se mantenha motivado e incentivado em compreender o conhecimento científico e as diferentes formas de chegar as coisas do nosso cotidiano através desse conhecimento, facilitando assim a aprendizagem.

A partir do momento em que ola alunola tem a oportunidade de visualizar o que acontece nos laboratórios, como determinado cientista chegou a descobrir como ocorre certo fenômeno, por exemplo, elela pode criar seus próprios conceitos sobre aquele conteúdo, facilitando a memorização deste, pois a experiência da prática pode ser algo mais palpável, mais próximo da sua compreensão, do que apenas palavras ditas ou lidas. 
A experimentação é importante, mas não deve ser a única ferramenta para auxiliar o aprendizado. É preciso trabalhar a contextualização, problematização, entre outras estratégias de ensino.

A experimentação deve ser compreendida como uma ponte que pode facilitar a aprendizagem, através dela pode-se discutir os fenômenos e os conceitos científicos que os norteiam, em busca de uma aprendizagem mais significativa.

A sexta questão pedia para que fossem diferenciados os tipos de experimentação, e como era de se esperar, ambos os entrevistados possuíam uma visão semelhante sobre esse tipo de atividade o que leva a acreditar que, mesmo com toda uma mudança tecnológica o conceito ainda continua o mesmo. Eis a questão e algumas das respostas: Diferencie experimentação investigativa, ilustrativa e problematizadora.

A Ilustrativa seria a experimentação conhecida como "receita de bolo", na qual busca apenas verificar como ocorre certo fenômeno, por exemplo. A investigativa, acredito que seja aquela em que os/as alunos/as são estimulados a criar hipóteses de como o fenômeno ocorre. Já a problematizadora, como o próprio nome já diz, propõe a resolução de um determinado problema, podendo este pertencer ao cotidiano, ou seja, de forma contextualizada com a realidade do/a aluno/a.

Na experimentação investigativa o aluno é instigado a fornecer hipóteses, dedução, levantamentos dos dados e conclusão, nesse caso o aluno não é um mero executor do experimento, mas um agente participativo que formula argumentos e desenvolve o trabalho a partir de uma investigação científica. A ilustrativa está apenas voltada para a demonstração do experimento, não participação dos alunos e muitas das vezes encontra-se direcionada para comprovação de teorias. E a problematizadora é semelhante a investigativa, mas, acredito que a diferença está que nesse tipo de experimentação é fornecido um problema inicial e o experimento deve estar relacionado a solução do problema, nesse caso o aluno também é um agente ativo e o professor um mediador do processo de ensino-aprendizagem.

Assim, a partir dos discursos acima, notasse que a visão indutivista do método científico, embora atualmente rejeitada pelos filósofos da Ciência, permanece presente no ensino de Ciências [12]. Isso ocorre pelo fato do indutivismo fazer parte de um processo que conduz as práticas da observação, principalmente nas atividades no laboratório.

A última indagação foi: Você sabe diferenciar a experimentação real da experimentação ideal? Justifique. As respostas a essa indagação foi a mais esperada porque o questionamento foi um dos motivos que levaram a desenvolver esse artigo e, como já era esperado, seja pela visão simplista, seja pela abordagem carente na formação inicial de professores, uns desconhecem ou simplesmente não sabe conceituar, como três dos entrevistados e outros pelos conceitos definidos anteriormente, buscaram defini-las.

Eu acho que a experimentação real é quando se realiza uma atividade experimental e que essa leva em consideração a alguns fatores que pode influenciar no resultado final do que se pretende. Já a ideal seria no sentido de comprovar a conhecimento científico sem que haja alteração no resultado final.

Acredito que a ideal é aquela associada a experimentação voltada para atividades relativas a vida cotidiana do aluno, ou seja, com algo que tenha relação com suas necessidades. 


\section{CONCLUSÃO}

A realização de atividades experimentais no ensino de química representa uma ferramenta de grande importância para que o aluno estabeleça uma relação entre a teoria e a prática, e leve a concretização do conteúdo abordado. Nesse sentido, a partir da análise das respostas apresentadas pelos professores entrevistados, é possível identificar que alguns deles ainda utilizam a experimentação como comprovação de teoria, e mesmo sabendo como diferenciá-las e compreendendo as suas funcionalidades, não procuram correlacioná-las.

As atividades experimentais são entendidas como situações na qual o aluno faz conjecturas, expõem seus pontos de vista e suposições, além de proporcionar uma maior interação com os demais colegas. É evidente que atividades experimentais oferecem condições para que os alunos possam testar suas suposições sobre conceitos científicos que ocorrem no seu cotidiano. Mas, a idealização dessas atividades ainda está longe da realidade, por conta das dificuldades encontradas nas escolas. Essas dificuldades podem ser relacionadas com a falta de laboratório e materiais, como também a carência de fundamentos teóricos, que podem ser justificados pelas lacunas derivadas dos cursos de formação de professores. Atualmente, entende-se ainda que esses empecilhos sejam encarados como deficiências naturais.

A experimentação real é caracterizada por essas dificuldades levando a desmotivação de alunos e professores, sendo apenas um instrumento de mecanização do conhecimento. Já a experimentação ideal, idealizada por vários estudiosos tem como característica principal a promoção do saber, onde é possível fazer a interligação de atividades ilustrativas, investigativas e problematizadoras.

Mesmo com tantos empecilhos, é necessária uma reflexão sobre a importância das atividades experimentais na construção do saber, uma vez que, ao se ministrar aulas teóricas como uma única metodologia, os alunos perdem o interesse e não conseguem estabelecer relações entre os conceitos científicos e o seu cotidiano. Porém, nos comentários dos entrevistados é possível perceber que na prática, os professores ainda utilizam a experimentação, mas como forma de demonstração e não como complementação do conteúdo, isso implica numa aprendizagem de memorização e não levando a resultados desejáveis e significativos, e muito menos a formação de um cidadão com postura crítica e reflexiva. Por isso, é necessário que os professores vejam a atividade experimental como uma metodologia que pressupõe uma aprendizagem significativa.

Logo, a experimentação ideal está longe de ser realizada em sala de aula, porque, além das dificuldades encontradas nas escolas, muitos professores resistem em modificar a sua metodologia de ensino.

\section{REFERÊNCIAS BIBLIOGRÁFICAS}

1. Silva LHA, Zanon LB. A experimentação no ensino de ciências. p. 120-153. In: Schnetzler RP, Aragão RMR. Ensino de Ciências: Fundamentos e Abordagens. São Paulo, CAPES/UNIMEP, 2000.

2. Filho JPA. Atividades experimentais: do método à prática construtivista [Tese de doutorado]. Florianópolis: Universidade de Santa Catarina, 2000.

3. Hartwig DR, Junior WEF, Ferreira LH. Experimentação Problematizadora: Fundamentos Teóricos e Práticos para a Aplicação em Salas de Aula de Ciências. Química Nova na Escola. 30, 2008. p. 34 - 41.

4. Oliveira JRS. Contribuições e abordagens das atividades experimentais no ensino de ciências: reunindo elementos para a prática docente.Acta Scientiae, v.12, n.1, 2010. p.139-153

5. Suart RC, Marcondes MER, Lamas MFP. A Estratégia "Laboratório Aberto" para a Construção do Conceito de Temperatura de Ebulição e a Manifestação de Habilidades Cognitivas. Química Nova na Escola. vol. 32, n 3, 2010.

6. Gonçalves FP, Marques CA. Contribuições Pedagógicas e Epistemológicas em Texto de Experimentação no Ensino de Química. Investigações em Ensino de Ciências, v.11, n.2, 2006 Disponível em: . Acesso em: 20 jan. 2016.

7. Delizoicov D, Muenchen C. Os três momentos pedagógicos e o contexto de produção do livro "Física". Ciência. Educação, v. 20, n. 3. Bauru ,2014, p. 617-638.

8. Guimarães LM, Aires JÁ, Gatto HS. Experimentação Problematizadora: Como são determinadas as quantidades de calorias nos alimentos. IX Congresso Internacional sobre Investigación en Didáctica de las Ciencias. Girona, 2013.

9. Tenreiro-Vieira C. Produção e avaliação de actividades de aprendizagem de Ciências para promover o pensamento crítico dos alunos. Revista Iberoamericana de Educación (ISSN:1681-5653). 
10. Silva MA, Martins ES, Amaral WK, Silva HS, Martines EALl. Compostagem: Experimentação Problematizadora e Recurso Interdisciplinar no Ensino de Química . Química Nova na Escola. São Paulo, vol. 37, $\mathrm{n}^{\circ}$ 1,2015. p. 71-81.

11. Santos GG et al. Tecnologia e educação: a influência dos sites no ensino de química. II Simpósio de Pesquisa e Extensão em Grupos Colaborativos e Cooperativos. Anais do Geem. ISSN: 2358-906X. Disponível em: https://proceedings.galoa.com.br/geem/geem2015/trabalhos/tecnologia_e_educacao_a_influen cia_dos_sites_no_ensino_de_quimica\#sthash.3Uu62y30.dpuf >. Acessado em: 04/07/2016.

12. Marconi M A, Lakatos EM. Fundamentos de metodologia científica. $5^{\text {a }}$ ed. São Paulo : Atlas, 2003.p. 201-202.

13. Galiazzi MC, Gonçalves FP, Rocha JMB, Schitz LC, Souza ML, Giesta S. Objetivos das Atividades Experimentais no Ensino Médio: A Pesquisa Coletiva como modo de formação de formação de professores de Ciências. Ciência \& Educação, v.7, n.2, 2001. p.249-263.

14. Gioppo C, Scheffer EW, Neves MCD. O ensino experimental na escola fundamental: uma reflexão de caso no Paraná. Revista Educar, Editora da UFPR, n. 14, 1998. p. 39-57.

15. Machado PFL, Mol GS. Experimentando Química com Segurança. Química Nova na Escola, nº 27, 2008

16. Piletti N, Rossato SM. Piaget: Desenvolvimento cognitivo e Aprendizagem. Psicologia da aprendizagem: da teoria do condicionamento ao construtivismo. São Paulo: Editora Cortexto, 2011. p. 65 - 79. 